\title{
Intraspinal meningioma in a four-month-old infant
}

Sir,

Meningiomas account for approximately $20 \%$ of all primary central nervous system (CNS) tumors in adults. In contrast, childhood meningiomas account for less than $3 \%$ of all primary CNS tumors. ${ }^{[1]}$ Spinal meningiomas have rarely been describe in infants. ${ }^{[2]}$ We report a fourmonth-old infant with thoracic extradural meningioma.

A four-month-old male infant presented with a twoweek history of a decrease in spontaneous movements in both the lower limbs. Prior to two weeks, the infant was able to push actively with his lower limbs and bear weight when held in the standing position. He is the fifth child of nonconsanguineous parents, the other four siblings are alive and well. The infant was born at term and the antenatal period was uncomplicated. The perinatal period was uneventful and the development 
was appropriate-for-age till the onset of the present symptoms. He was exclusively breast-fed. There was no family history to suggest neurofibromatosis.

On examination, the infant was afebrile and playful. His weight was $6.5 \mathrm{~kg}$, length $63 \mathrm{~cm}$, and head circumference $41 \mathrm{~cm}$, all at the $50^{\text {th }}$ percentile for age and sex. There were no neurocutaneous stigmata. There was no tenderness over the spine and no spinal deformity. Neurological examination revealed hypotonia in both the lower limbs with a motor power of $2 / 5$ grade. Tendon reflexes were brisk in the lower limbs with ankle clonus and plantar response was bilaterally extensor. The abdominal, cremasteric, and anal reflexes were absent bilaterally. Anal sphincter tone was lax. Withdrawal response to pain was normal in both the lower limbs. The rest of the clinical examination was noncontributory.

A clinical diagnosis of compressive myelopathy was made and further investigations were done. The plain roentgenogram of the spine was normal. Magnetic resonance imaging (MRI) of the spine revealed an isointense lesion in the posterior extradural space extending from T4 to T11 vertebrae on T1-weighted images. The tumor was extending from the left T8-9 foramen into the left paravertebral region. The lesion caused significant compression of the cord at T3-T11 level [Figures 1 and 2].

The infant underwent a T4-T10 laminectomy. The tumor was well separated from the spinal cord and could be resected completely with its dural attachment. Histopathological examination of the tumor specimen showed whorls of cells with indistinct cytoplasmic boundaries, intranuclear cytoplasmic intrusion (pseudoinclusion), and a psammoma body suggestive of meningothelial meningioma [Figure 3]. Following surgery the power in the lower limbs started improving on the third postoperative day and the power was grade $3 / 5$ by the seventh postoperative day. At discharge the anal sphincter tone was normal. At follow up after one month, the superficial reflexes were normal but the deep tendon reflexes in the lower limbs were still brisk with ill-sustained clonus. Power in the lower limbs had improved to grade $4 / 5$ at follow up.

Spinal cord tumor is an unusual cause of paraparesis in infancy; however, with the better availability of sensitive neuroimaging techniques, it is now possible to diagnose them early. Extradural meningiomas are uncommon and account for $2.7-10 \%$ of spinal neoplasms. ${ }^{[3-5]}$. The most common site of spinal meningioma is the thoracic spine. ${ }^{[5-8]}$ There are very few case reports in the literature describing intraspinal meningioma in children less than one year of age. ${ }^{[2]}$ Female gender predilection has been attributed to sex hormones, however, in the pediatric age group, spinal meningiomas have been reported to lack the female predominance. ${ }^{[9]}$ Contrast MR imaging is the best

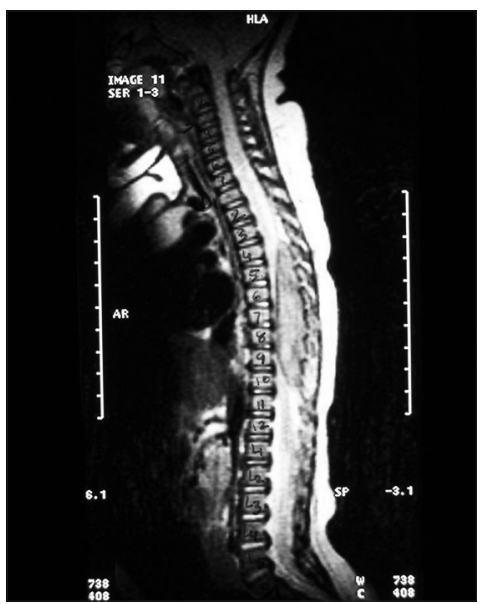

Figure 1: T2-weighted sagittal MR images showing a mass having an isointense lesion in the posterior extradural space extending from T4-T11 and causing mass effect on the spinal cord

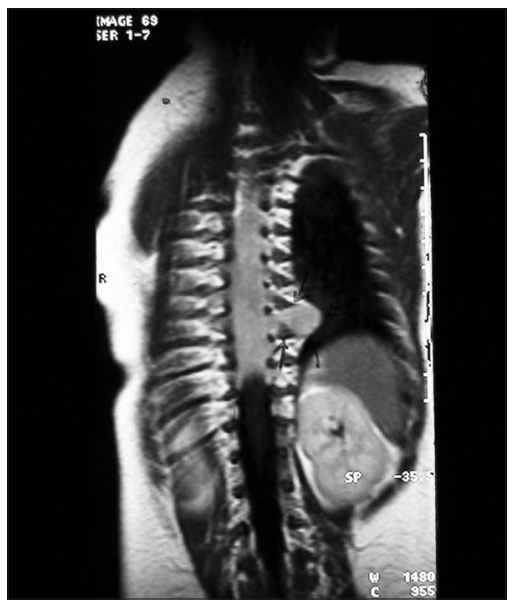

Figure 2: T1-weighted MR images showing a mass having an isointense lesion in the posterior extradural space and extending from the left T8-9 foramen into the left paravertebral region

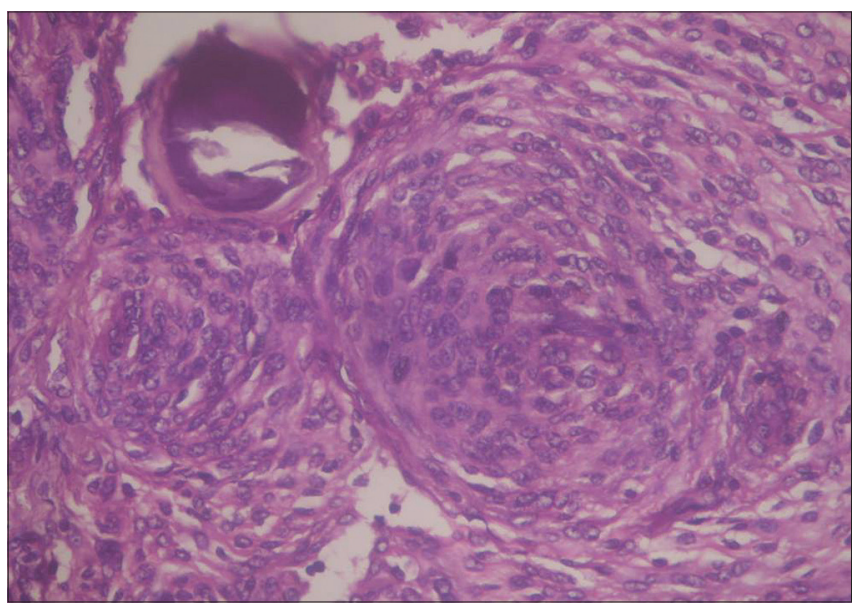

Figure 3: Pathology slides showing cellular whorls of cells with indistinct cytoplasmic boundaries, intranuclear cytoplasmic intrusion (pseudoinclusion), and a psammoma body. $\mathrm{H}$ and $\mathrm{E}$, original magnification $\times 400$ 
imaging modality for diagnosing spinal meningiomas. It clearly delineates the level of the tumor and its relation to the cord, which is useful in planning surgery. ${ }^{[7]}$

Surgery is the preferred treatment in cases of spinal meningiomas. Complete resection is possible in most of the cases and is associated with good postoperative functional improvement. ${ }^{[5-8]}$ This emphasises the need for an early diagnosis and an early referral to a neurosurgical center. Recurrence of the tumor is rare, and in most series the reported rate of recurrence ranged from $3.1-14.7 \% .{ }^{[--8]}$ Radiosurgery should be considered for the exceptional cases involving recurrent and symptomatic spinal meningiomas. ${ }^{[8,10]}$

\section{Syed Ahmed Zaki, Ravi T., Preeti Shanbag, Alka Kalgutkar}

Departments of Pediatrics and Pathology, Lokmanya Tilak Municipal Medical College and General Hospital, Sion, Mumbai - 400 022, India. E-mail: drzakisyed@gmail.com

\section{References}

1. Rushing EJ, Olsen C, Mena H, Rueda ME, Lee YS, Keating RF, et al. Central nervous system meningiomas in the first two decades of life: Aclinicopathological analysis of 87 patients. J Neurosurg 2005; 103:489-95.

2. Watanabe M, Chiba K, Matsumoto M, Maruiwa H, Fujimura Y, Toyama Y. Infantile spinal cord meningioma. J Neurosurg 2001;94:334.

3. Frank LB, Harrop SJ, Hanna A, Ratliff J. Cervical extradural meningioma: case report and literature review. J Spinal Cord Med 2008;31:302-5.

4. Bret P, Lecuire J, Lapras C, Deruty R, Dechaume JP, Assaad A. Intraspinal meningiomas. A series of 60 cases. Neurochirurgie 1976;22:5-22.

5. Levy WJ Jr, Bay J, Dohn D. Spinal cord meningioma. J Neurosurg $1982 ; 57: 804-12$

6. Solero CL, Fornari M, Giombini S, Lasio G, Oliveri G, Cimino C, et al. Spinal meningiomas: Review of 174 operated cases. Neurosurgery $1989 ; 25: 153-60$.

7. Klekamp J, Samii M. Surgical results for spinal meningiomas. Surg Neurol 1999;52:552-62.

8. Gezen F, Kahraman S, Canakci Z, Bedük A. Review of 36 cases of spinal cord meningioma. Spine 2000;25:727-31.

9. Erdinçler P, Lena G, Sarioğlu AC, Kuday C, Choux M. Intracranial meningiomas in children: Review of 29 cases. Surg Neurol 1998;49:136-41.

10. Roux FX, Nataf F, Pinaudeau M, Borne G, Devaux B, Meder JF. Intraspinal meningiomas: Review of 54 cases with discussion of poor prognosis factors and modern therapeutic management. Surg Neurol $1996 ; 46: 458-64$.

Accepted on 15-02-09 